\title{
PHILIPPINE VALUES IN THE SUPERMODERN/HYPERMODERN AGE OF THE INTERNET
}

\author{
Teresa Paula S. De Luna \\ Department of Speech Communication \& Theatre Arts, \\ College of Arts and Letters, University of the Philippines \\ Diliman, Quezon City, Philippines \\ (tsdeluna@up.edu.ph) \\ DOI: https://doi.org/10.22452/jati.vol24no2.4
}

\begin{abstract}
Hypermodernity is a condition through which we are overwhelmed with so many interests and where pursuits in life are reflected in the age of the Internet. The Internet and Internet-mediated-technologies produced both by it and from it represent a hypermodern existence that impacts how various Philippine values are currently performed. This paper focuses on two facets of the formation and development of the Philippine values system: the socio-historical perspective, and the impact of technological innovation on the way we perceive ourselves that extends to how we socialise with each other in our communities. It discusses how the Philippine values system had been formally and technically incorporated into the 'mainstream' discourse on the Filipino identity and revisits the proffered lenses within the context of a hypermodern space where the Internet, a technological development that disrupted the everyday life of Filipinos in the $21^{\text {st }}$ century, is present. The narratives of students from the University of the Philippines (UP) concerning their immersion into the Internet world are examined to identify the impact of Internet technology on their current values system. The findings reveal how different, yet similar UP students are in their dispositions on being a UP student. The values they possess are reflected in the stories they share on what UP is to them and what it means to be a UP student. Identity and nationhood come up as facets of the understanding and practice of UP Diliman students of their values system. The Internet has functioned as, and will continue to be a venue where discussions on our identities (not a single one anymore) as Filipinos and our nationhood transpire. Ultimately, these communal socialisations continue to remind us who we are and what we have become as Filipinos.
\end{abstract}

Keywords: Philippine values system, culture, Internet-mediated technology, supermodernity/hypermodernity 


\section{Introduction}

The importance of a set of values and its system, in every and any society, is an established reality. It is considered as a social structure that shapes and reproduces identities. Therefore, we always take an interest in finding out the 'history' of the values we adhered to, those we currently stand by, and the ones that will endure as our culture and society progresses.

The values that are constructed and conditioned in the socio-cultural system of a community are absorbed and performed by its members. Typically, values are passed on from one generation to another. The community's ideals and principles are reproduced and reified in the various ways we live our lives. Hence, the very essence of the existence of the values system is anthropological. Values guide us in the conduct of our everyday life and make sense of why we do the things we do. However, in order for us to gain a deeper discernment of values, we probe the context and circumstances of where these are created, developed, reified, reproduced, and modified in the history or histories of our socio-cultural communities.

This paper focuses on two facets of the formation and development of the Philippine values system: the socio-historical perspective, and the impact of a technological innovation concerning the way we perceive ourselves that extends to how we socialise with other people in our communities. It discusses how the Philippine values system had been formally and technically incorporated into the 'mainstream' discourse on the Filipino identity. It also revisits the proffered lenses within the context of an anthropological place where the Internet, a technological invention that disrupted the everyday life of Filipinos in the $21^{\text {st }}$ century, is present.

\section{Philippine Values System in the 1960s}

How do we describe the Filipino? What does it take to be called a Filipino? Indeed, we claim that we have different identities. These identities may be attached to our various ethnicities as determined by our geographical origins or maybe imagined (Anderson, 1983) as 'one people' for one Philippines. It is within the latter's viewpoint that this article takes off. As 'one people' we locate our identities even before the Spaniards came. Our selfhood continued to be influenced when we were colonised by several foreign countries, namely Spain, America, and Japan. It is supposed, as written in quite a number of books and scholarly works, that, as a result of our serial colonisation, our identities were 'colonised' as well. The way we think and act is 'inspired' and 'inconspicuously manipulated' by the colonial ideologies. Hence, when they physically left our 
country, we were excited to discover who we were as a group of people and to discern what makes us Filipinos outside the clutches of our colonisers' sociocultural conditioning.

The study and practice of anthropology during our colonised years were focused on the 'other'. The colonisers wanted to learn about the cultures of their colonies with the aim of subjugation; hence, they wanted to know how to go about it in the most effective and least stressful manner. Anthropology was in a sense used as a tool to achieve this. By learning how the 'other' 'behaves', colonisation with the least resistance from the 'natives' will most likely be realised. When the era of colonisation ended, a dilemma arose: what happens now to anthropology as a discipline and practice? What should be the motivation and preoccupation of 'colonial' anthropologists in the post-colonial scene in which the Philippines no longer has the Western anthropologists who were physically and socio-culturally different from the natives they were 'studying'? In their place were the 'native' anthropologists who were educated within the colonisers' paradigm and pedagogy. After completing their education, these new anthropologists began their quest for the Filipino identity.

A vital fragment of our Filipino identity is our set of values. Our performance of our values and principles provides a tangible illustration and demonstration of our being Filipino. It is no surprise then, that after the Second World War, specifically during the 1960s, Filipino scholars took an interest in this subject matter.

In the 1960s, there was a preoccupation of scholars in the social sciences, including Anthropology, on the Philippine values system (Magos, 2004). Initial works on the examination of the Filipino values and the Philippine values system include Kaut's (1961) analysis of utang na loob, as a system of contractual obligation among Tagalogs, and Hunt's (1963) exploration of the values in the Philippine social setting. Attention on the "Utang na loob" Filipino trait was extended to other values, such as smooth interpersonal relations (SIR) (Lynch, 1970, as cited in Hennig, 1983), hiya, pakikisama (Bulatao, 1964), and amor propio (Hollnsteiner, 1970). Socio-political upheavals marked the 1960s and 1970s, which "sparked the crisis of meaning in anthropology" (Tan, 2010 p. 16). According to Tan (2010), this was the beginning of the post-anthropology age, a shift from the discipline's attachment to the colonial agenda to "crisis representation".

There were two schools of thought in making sense of our 'being a Filipino': the Institute of Philippine Culture (IPC) from the Ateneo de Manila University (ADMU), and the group of social scientists represented by Sikholohiyang Pilipino (SP) from the University of the Philippines (UP), who 
negate the claims of the IPC. The former was the group that set off the discourse during the 1960s, while the latter challenged the IPC by submitting an alternative paradigm as a basis of determining the Filipinos through their values system. The IPC was the centre for values research when the interest in the Philippine values system first brewed during the 1960s (Tan, 1997). The interest is linked to the '1960s modernisation theory', which was the trend in the social sciences when the economic state of the Philippines was perceived to be inferior to that of the modern industrialised societies, such as the United States and United Kingdom. Specifically, the Philippines back then was considered to be a third world or 'underdeveloped' country. The question of the IPC was "Why are we an underdeveloped country and what is wrong with us?" After several years, when political correctness became a dominant discourse that highlights sociopolitical sensitivity, the "third world" label was replaced by the "developing nation" terminology (Tan, 1997). Most of the Filipino scholars who wrote about Filipino values were mostly trained abroad and thus influenced by Western theoretical framings, such as those of McClelland (1961), Banfield (1958), and Talcott Parsons (1964) (as cited in Tan, 1997). These perspectives had a premise of economic dichotomies - 'good vs. bad state of living' and the 'modern vs. backward'.

Initial studies on Filipino values during the 1960s were criticised as being Western framed. This was countered by arguments and proposals of looking at the Philippine values system in an etic point of view. Thus, the scholarly works on our values system became structured in an "argument vs counter-argument" framework (Hennig, 1983). For instance, Jocano (1966) contradicted Lynch's (1970) SIR by citing that Filipinos also employ hostile attitudes (strategies) during social interactions. This was again counter-argued by Lynch, stating that more Filipinos favour SIR to attain the "ultimate Filipino values", such as social acceptance, economic security, and social mobility (Lynch, 1970), rather than using hostility as a social strategy (Hennig, 1983). SIR was further emphasised by Hollnsteiner (1970) by putting forward "reciprocity" as a mechanism to maintain SIR. Shame would be the result of a breakdown in reciprocity (as cited in Hennig, 1983). However, according to a number of scholars, there is still a suggestion of indecisiveness in terms of qualifying such values in the variety of situations and contexts in which Filipinos engage. Hence, some academics, especially from the emic vantage point, maintain that there is a "certain tentativeness relative to Filipino values even among the most prominent authors on the topic" (Hennig, 1983).

During the first part of the 1970s, a new trend came about in the social sciences: anthropology that concentrated on the "Filipino soul and psyche" in 
search of the most truthful presentation and representation of the Filipino (Magos, 2004). SIR was perceived as an intermediate goal to get to the ultimate values. However, this was countered by a different framing by UP's Enriquez, Salazar, Jocano and Covar - social scientists who were mostly educated and trained abroad - who worked on providing a 'new' way to view our personhood as Filipinos. Jocano insisted on employing a local framework in examining ourselves and our culture. In his article "Re-thinking Smooth Interpersonal Relations" (1966), where during his fieldwork he observed how Filipinos engaged in constant fighting, he put forward that perhaps the idea of SIR was mostly implanted by the Americans since they seem to be the ones overly concerned with SIR. Lawless and Tan (1968) critiqued the methodological procedures utilised in the investigation of the Philippine values system that mostly led to the propagation of stereotypes between Eastern and Western societies. Enriquez, who is known for his contribution to the indigenisation of social science and Filipino Psychology, suggests using indigenous methodologies (Enriquez, 1979). SP is considered to be the antithesis to the 1960s Ateneo-IPC values research (Tan, 1997). Unlike the IPC's modernity and economic freedom, SP's ideology is based on nationalism, which is said to be derived from Constantino's idea that the "causes of our present problems are our past colonial experiences" (as cited in Tan, 1997). SP's methodologies were positioned to oppose the IPC. However, SP is criticised as being predictable "along the lines of the richness, complexity and innate goodness of the Filipino vis-à-vis the malicious intents of our former colonial masters" (Tan, 1997).

Historian and anthropologist Salazar, however, critiqued the concept of 'indigenisation' extended by some of the proponents of SP as being mainly based on, and a reaction to the Western framework. Hence, it only fortifies 'othering'. Covar's Pilipinolohiya emphasised using local language in encoding and decoding local knowledge (Magos, 2004, pp. 342-343). He used a Manuvu jar as a metaphor for the Filipino personhood. It has three parts - loob, labas, and lalim (depth) (Covar, 1995).

Probing and comparing the two schools of thought on the Filipino values system from ADMU's IPC and UP's SP, arguments for and against may probably turn tautological, since the basic premises of their claims are different. The IPC's discussion of Filipino values is strongly hinged on economic modernity, while $\mathrm{SP}^{\prime} \mathrm{s}$ is linked to nationalism and nationhood. Paradigms and pedagogies employed by the IPC are largely based on Western framings. On the other hand, $\mathrm{SP}^{\prime} \mathrm{s}$ take on what makes the Filipino is based on local understanding/perspective, which is based on interpersonal relations and indigenous knowledge. Mostly, discourses during this time adhered to and are 
attributed to the differing ideologies and purposes of the two factions: the IPC is economy-oriented while SP is focused on the 'recovery' of nationhood. In other words, there is a difficulty, as it is futile to set them in opposition to each other since they do not argue on the same plane. As a result, most of their claims and contentions end up as mere reactions and counters against each other. It is in this light that Hennig, in his article "Philippine Values in Perspective: An Analytical Framework", suggests another way of perceiving Philippine values by first recognising that the Filipino values system is a product of a "culture emerging from a synthesis between historic and prehistoric Asian values and the impact of Western values especially during the American occupation" (Hennig, 1983).

The interest in the Philippine values system in the academic community has slightly waned over the years. The reason perhaps has something to do with the "never-ending" debates without arriving at an agreeable (for both sides) compromise (Hennig, 1983). Then again, perhaps the very nature of any values system should be examined to explain why it is always perceived as provisional. Making sense of values systems is always contingent on the 'current' social, cultural, and political context of the community. What preoccupies community members at the moment, what is important to them?

Fast forward to 2005. Yacat (2005) researched Philippine values guided by the SP framework and Covar's Loob at Labas methodology in probing the question "Who is the Filipino?" He emphasised the role of cultural identity (not just national identity) in determining who the Filipino is. Although the study is conducted and analysed within the lens of Psychology, its overall results tackle a collective set of human behaviours - values. Yacat's discussions brought us back to the 1960s-1970s debate. He floats the conclusion that understanding the concept of national identity is a complicated and contested undertaking that brought about positive and negative consequences throughout the ages (Salazar, 1998 as cited in Yacat, 2005). National identity is usually discussed within the contexts of intergroup tensions and or the production and reproduction of stereotypes (Yacat, 2005, p 20). In the Philippine setting, national identity and issues related to it are attached to the socio-political-historical context. Contributions from Constantino's discourse on the miseducation of the Filipino, Enriquez (1979) evaluation of Filipino values, and Doronila's (1982, 1989 and 1992) empirical studies on national identification (as cited in Yacat, 2005) show how we Filipinos locate our understanding and appreciation of national identity.

Yacat, however, in his relatively recent investigation differentiates national identity from cultural identity. He employed a cultural perspective that looks at culture as a process of meaning-making that involves five "moments": representation, identity, production, consumption, and regulation (Du Gay, Hall, 
Janes, Mackay, \& Negus, 1997). He employed three thematic contexts in which he examined Filipino values: pinagmulan (socio-political dimension); kinalakhan (cultural dimension); and kamalayan (psychological dimension). The central questions asked were "Are you a Filipino?" and "Why do you say so?" The results show that being Filipino is usually unexamined, assumed, and naturalised. When asked to further explain, the following is revealed, a Filipino is someone who recognises and accepts the 'Self' as Filipino, takes pride in being a Filipino, recognises and accepts fellow Filipinos, has empathy for fellow Filipinos, and is involved in the affairs of fellow Filipinos.

Yacat's (2005) inquiry shows how we Filipinos continuously negotiate our 'being' Filipino in a variety of contexts because it is unexamined, while, at the same time, it is assumed and naturalised. The former two are products of social conditioning, while the latter is the ambivalent part of understanding the Philippine values system. 'Assumed' means we accept that what is written in textbooks and fed to us by the 'dominant' groups in society about how we 'should behave' are true. 'Naturalised' would mean that for a number of years we have been following what the 'dominant' groups in society prevail on us, and, hence, we succumb to the belief that these values are 'given, normal, and expected'. Yet these values are considered to be 'unexamined'. What kind of examination do we need to conduct to find out what kind of values Filipinos have?

\section{Theoretical Lens}

\section{Technology and Values System}

Many variables may be examined that can explain why values are affected by contradictions and inconsistencies. Technology is one such variable. The impact of technology on the conduct of our everyday life is reflected in the values we express in our actions.

Through the years, since the beginning of the interest of Filipino scholars in our values system, technological innovations have been developing in our society, and, consequently, affecting how we manage our daily habitual living. One such technological invention that has drastically altered our being human is the Internet. The Internet has unsettled the spaces where we perform our being human, and, therefore, it follows that it has also disturbed our impression and expression of our values and principles as Filipinos.

What happens when the Internet infiltrates the conduct of our everyday lives? Are the values proffered during the 1960s and 1970s by both the IPC and $\mathrm{SP}$ still present in the new extended and expanded spaces (because of the Internet) in which we Filipinos intermingle? This article examines narratives of 
the students of UP Diliman pertaining to the human to machine relations they have with gadgets that allow them to enter cyberspace, the socialisations they engage in via online spaces and other needs that are answered by the Internet along with its Internet-mediated technologies (IMTs).

\section{Culture Change}

Changes in the way we live our lives are unavoidable. How these changes will transpire and be carried out are almost always dependent on our beliefs, principles, and ideologies in life. These philosophies, which are inculcated in our system from when we are born and while growing up, guide and inform our personal and social actions. Our socio-cultural system, which is composed of social structures makes possible for the manifestation of our values in different contexts. For instance, social conditions somehow direct how the IPC's SIR (Lynch, 1970) should be carried out, and what acts are permissible and will most likely create this social environment where we gain the 'ultimate values' of social acceptance, social mobility, and economic security. On the other hand, how can we perform our nationhood? What mechanisms embedded in our social structures maintain and propagate our values and strengthen our nationhood? Bourdieu's (1990) habitus explains this process of cultural modification. The habitus' "structured structuring structures" in a society that form and develop our dispositions may reproduce our embodied values or may also transform our conduct of life (Bourdieu, 1990). Socio-cultural alterations occur when "something new" is introduced to the community. In this instance, the Internet is that new component that has been adopted by community members.

Our adoption of and adaptation to the Internet has impacted our community including the social systems and structures that operate it. Because of the Internet, our social world has become more supermodern/hypermodern. Augé describes supermodernity/hypermodernity as a state and stage in a society of "overabundance" (Augé as cited in Gebauer et.al, 2015). Overabundance refers to the excessive material, technological, and social 'happenings' that we partake and in which we engage. A supermodern society, he says, is composed of spatial abundance... overabundance of events and increased manifestation of individuality, which is attributed to the increased possibilities of moving to and moving around spaces and places, and to the proliferation of agencies for interactions and socialisations (Paans, 2011). Supermodernity is characterised by a transient, transitory, and permeable existence (De Luna, 2017). Although Augé originally located the idea of supermodernity during the time when the Internet was not as popular as it is nowadays, and when its technology was not as sophisticated and wide-ranging as we presently know it to be, he was already 
able to capture the resulting state of sociocultural context to which the Internet will give birth. Augé originally referred to parking lots and airports as the consequent spaces of supermodernity. He calls these spaces non-places in that there is almost an absence of social interaction, and because they do not contribute to the identity or inform history. On the other hand, he talks about anthropological places as the opposite of non-places (Augé, 1995). Although at first glance online spaces may seem to be non-places, if we probe deeper, due to the variety of socialisations and interactions that we join in different online spaces, one may say that cyberspace is also a site where we shape ourselves. Again, values are fundamental components in determining our selfhood and nationhood. What then is the impact of the Internet on the production, reproduction, or modification of the Philippine values system?

\section{Methodology}

\section{The Internet and the Philippine Values System}

To find out how much impact (if there is) the Internet has on the Philippine values system, I interviewed twenty University of the Philippines Diliman (UPD) students on their immersion into the Internet world. I wanted to know the depth or shallowness of their embodiment of the Internet and other technologies because of the Internet. Subsequently, I examined how this embodiment is positioned in the students' habitus. The findings reveal how different yet similar UPD students are in their dispositions on being a UPD student. The values they possess are reflected in the stories they share concerning what UP is to them and what it means to be a UPD student.

\section{Discussion}

\section{Before UP}

Before being part of the UP community, the disposition of my informants of the university mostly came from their parents and relatives. They all agree that being part of UP is an honour and a privilege. A number of my informants state that being at UP is a responsibility. It is likened to an obligation that has to be fulfilled, such as 'continuing the tradition' of the family, which is composed of UP graduates. For some students who are the first to become UP students in the family, they also feel the burden of 'making it good' in UP since they have suddenly become members of the clan who have to maintain its "impressive" reputation. Although UPD students initially welcome this responsibility with pride, there are times when this "positive" circumstance becomes a burden for 
them. Students feel this the most when they are 'having a hard time' managing their academic and non-academic UP life (value of family).

\section{Being UP}

The life of a UPD student is hard. It is typically during difficult times that our values and principles are displayed the clearest and strongest. It is through the experiences of hardships that close communal interpersonal relations are forged and maintained, while it is through 'sufferings' that we feel the need to belong and identify with something or someone, and it is through the collective experience of an anthropological place that we create or contribute to history.

Being a UP student from the perspectives of the UP students themselves centres on the aspects of the quality of UP education and the quality of UP students. The current UPD students think that UP and UP students belong to these categories of conditions and attributes: honour and excellence, matalino (intelligent), may pinaglalaban (have something to fight for), masipag at madiskarte (hardworking and resourceful), astig (strength in character), and affordability. These perceptions relate to pride towards one's identity and abilities, love for one's country and fellowmen, and awareness of the realities of life.

The UP student is thrust into engaging in different interpersonal interactions. Some of these exchanges may be at the personal level while most are within the context of being a student of a big and daunting academic institution. When students enter the university, they try to keep and maintain the state and conduct of their previous relationships while embarking on establishing new ones. They carry with them values that guide them in how they "participate" in these relations. The Internet, an unavoidable technology that is useful in both academic and non-academic settings, plays an important role in how UPD students navigate university life, especially when it comes to interpersonal relations. Connectivity, communication, and extension of selves are the areas in their day-to-day activities where the Internet has gained access, and, consequently, shaped their dispositions.

The Internet has effected a change in the way we connect and communicate with each other. One student reveals that he is more comfortable communicating online than offline. He shares that he has two personalities on the Internet: one for those who he interacts with in both offline and online social spaces and another for those he met and communicates with online. However, some claim that their relationships do not change because of the Internet. The Internet for them is an avenue to extend and expand their lives. One student says, "I usually talk to the same people... we just continue what we talk about whether online or offline." The Internet has opened spaces where we exercise our being human. Consequently, it has created additional existences that may be 
considered as extensions of the traditional offline lives. Students relay how IMTs have added dimensions to almost all aspects of their lives.

There are three areas of their lives that have been greatly impacted by the Internet: self-realisation, family, and friendship. Due to engaging in the online world, students have come to realise several issues and points about their identities and personhood, especially when they compare their online selves to their offline personalities. Students' family relations are also impacted by IMT, especially for those who have permanent addresses in the provinces, as IMTs give them assurance and comfort that they remain connected and can still function as a family despite the barriers of time and distance. UPD students find the Internet vital in connecting with family and friends. Through Facebook and Skype, these UP students are able to ensure that their relationships with their loved ones are nurtured. Some refer to this act as maintaining social obligations that extend to their former friends in high school. Technology has made it possible for us humans to invent a variety of ways of communicating. The Internet has produced and continues to produce different avenues for communication and interaction between and among people. Friendship is one of the initial aspects of students' lives where IMT has permeated. The current students were typically initially introduced to the Internet world through gaming and social media. Internet gaming made students relate to 'strangers' as if they are friends and acquaintances since all the gamers have the same goals and respect and follow the same 'rules of the game'. They share a sense of affinity towards one another even if they do not know much about each other in the face-to-face setting. Friendster, a defunct social network platform, is one of their earliest memories of engaging with IMT. It is also through this aspect of their lives that they feel that IMT has had a considerable impact.

Just like any social space, rules are inevitably, albeit sometimes unintentionally, established by those who circulate and create communities in these spaces. Although all rules navigate both offline and online, my informants clarified through which spaces these rules are initiated and generated. There are specific online circumstances that necessitate online imperatives, such as listeners' expectations on feedback, i.e. meanings attached to how you respond online, such as when you do not respond right away means something or when you do not respond at all, etc. Due to the effect of IMTs on our daily activities, we have the tendency to preserve what we are used to and resist change. For instance, a student laments that "time is lost online". This statement may suggest a certain longing for a face-to-face intermingling with loved ones, even with those who we are not very close. It may also refer to not being able to manage time since there are so many online spaces to go to, and one tends to forget how 
much time is already spent in cyberspace. However, all the students I interviewed agree that both online and offline realities have melded, in that when offline and online spaces intersect the realities of both realms are melded.

Since interpersonal relations have been affected by the presence of the Internet in the everyday existence of students, students' perceptions of their own lives are also impacted. Their accounts and outlook on the specific bearing of IMTs include both positive and negative sentiments. In order for UP students to survive and succeed UP they must be responsible. Responsibility not only concerns academic work but everything that affects and implicates the life of students while they are undergraduates of the university. This includes nonacademic activities, such as organisation work and occasions in which family and friends are a part. A student explains that somehow it is inevitable to go online because it is part of being a responsible student/classmate since these platforms are needed to complete group projects. For instance, the use of Google Docs where all group members can write and collaborate in real-time in composing a group paper. Personal sentiments are also involved in the students' utilisation of and adaptation to IMT. This is inevitable since IMT is implicated and enmeshed in everyday life of the everyday student users. A student comments that arguments that arise online are more difficult to resolve compared to the face-toface scenario since they are "less personal" and therefore "less sincere". Apprehension is a specific emotion that is highlighted as a "negative" impression that the Internet generates. There are many apprehensions that UP students may have about the Internet, including those that relate to safety and security, the ability to focus, health, and distractions, as well as trade-offs and other discoveries.

a. Safety and Security - Cybersecurity is almost everybody's concern, and most UPD students worry about false representation, which mostly transpires on social media.

b. Focus and attention - The students' ability to concentrate and stay focused is sometimes compromised by the Internet because there seem to be so many things to which they must attend.

c. Health - Due to the many things that students have to do in the melded offline and online world, sometimes their health is also affected, such as their inability to concentrate and lack of sleep due to the numerous tasks and interests in which they have to take part. 
d. Distractions - With the variety of stimuli available, students are challenged in terms of how to manage their time and resist distractions so that they can accomplish the tasks they have to undertake.

Along with these themes that emerged from the narratives of UP Diliman students about their experience of the Internet, several remarks, observations, and judgments arose that provide us with a clearer perspective of how the Internet affects our existence. A student observes that due to the convenience offered by IMTs, people are no longer used to having difficulties in getting things done, "hindi na sanay mahirapan" (not anymore used to hardships). Someone affirms this by saying that people want things done easy and fast, "gusto ng mga tao agad-agad" (people want instant gratification); the value of patience is lost. Another imparts that there are less face-to-face "chickahan" (chit-chat) because of too much focus on online activities. In relation to the impressions concerning what has become of the attitudes and behaviours of people when they present themselves and interact with one another online, one student expresses dismay by his discovery, "Marami palang walang kwenta... (haters and people displaying superiority over other people), "tuloy, nag-ha-hate na rin ako" (this makes me hate too). Another student reinforces this feeling by stating, "Dami pa lang ignoranteng tao! (there are many ignorant people), "it has degraded my faith in humanity" (referring to believers of fake news)."

\section{Conclusion}

\section{Moving forward}

In examining the narratives of the students, what values are identified that govern and regulate the life of a UP student within the merged online and offline social world? UP students value their selfhood individually and collectively. They have pride in their identity as individuals who navigate both the Internet and the physical worlds. They think highly of their schoolmates whom they perceive as also adhering to the tenets of honour and excellence and social consciousness; hence, they also view themselves in connection with the UP community to which they belong. They are proud to be UP students because they receive the best education without having to pay exorbitant tuition fees compared to the other universities in the Philippines. However, they are most proud of being a UP student because their parents are proud of them. Although UP students understand that technology makes one's life 'easier' or more comfortable, they are equally aware that there are trade-offs for the comfort and convenience, such as the lack of depth of communication they have with loved 
ones. The Internet also affects their social relationships, whether favourably or unfavourably. Opinions on the subject matter reveal how students value relationships in the community.

Do these values seem familiar? Do they resemble the values submitted by both the IPC and SP? Are there new values that emerged due to the Internet? The IPC proposed that the ultimate values of Filipinos are social acceptance, economic security, and social mobility. It would seem that in this hypermodern online and offline existence, social acceptance is no longer given importance. Perhaps social acceptance during the time the IPC presented these values was contextualised in just 'one society', a single social space in which everybody is located. However, the many varied spaces that the Internet has generated has provided individuals as many socio-cultural spaces as they can handle. It is also true that the IPC's SIR are still considered essential in living a communal life, but there are circumstances on the Internet, especially in social media spaces, in which offline social rules are bent, and even disregarded in cyberspace. Economic security is still considered central amongst students since they associate being in UP with a (financially) "good future". This idea is of course already implanted in them by their parents even before they became UP students. There is also the parental influence on their idea of (financial) success. Perhaps this is the reason why students view that having access to the Internet assists them in their schoolwork, and gives them an extra advantage in getting a high grade. Graduating with high grades relates to getting financially stable jobs. On the other hand, the Internet opens the doors for creativity and innovation that can also translate to "success". Social mobility, on the other hand, can now be achieved in many ways compared to the social conditions during the 60s and 70s. One does not have to be a doctor, a lawyer, or an engineer to be successful. Internet innovations have given opportunities for people to gain success in 'new' fields, such as information technology, and other Internet/online-based businesses.

How about national identity and nationhood? Since it is apparent that UP students take pride in being part of an institution expressed in both offline and online spaces, has the Internet technology contributed to their propagation? This extends from the UP identity to the Filipino identity. I believe that the Internet may have and will continue to function as a venue where discussions on our identities (not a single one anymore) as Filipinos and our nationhood can transpire. Ultimately, these communal socialisations will continue to remind us who we are and what we have become as Filipinos. 


\section{Acknowledgements}

This paper was presented at the $8^{\text {th }}$ International Conference on Southeast Asia (ICONSEA 2019), Faculty of Arts and Social Sciences, University of Malaya. The author would like to acknowledge the University of the Philippines Diliman's Department of Anthropology where the concept of this paper was developed and the Department of Speech Communication and Theatre Arts for the aid that made the presentation of this paper possible.

\section{References}

Anderson, B. (1983). Imagined Communities Reflections on the Origin and Spread of Nationalism. London: Verso

Augé, M. (1995). Non-Places: Introduction to an Anthropology of Supermodernity. London: Verso

Banfield, E C. (1958). The Moral Basis of a Backward Society. USA: The Free Press Bourdieu, P. (1990). The Logic of Practice. Stanford, CA: Stanford University Press. Bulatao, J. (1964). “Hiya”. Philippine Studies, 12(3), 424-438.

Covar, P. (1995). Unburdening Philippine Society of Colonialism. Diliman Review, $43(2), 15-20$.

De Luna, T. (2017). Networked Iskolars: An Inquiry on the Internet as an Anthropological Place Embedded in the Melded Socialities of University of the Philippines Students. Ph.D Dissertation, College of Social Science and Philosophy, University of the Philippines, Diliman, the Philippines.

Doronila, M.L. (1982). The Limits of Educational Change. Quezon City: Universityof the Philippines Press.

Doronila, M.L. (1989). Some Preliminary Data and Analysis of the Content and Meaning of Filipino National Identity among Urban Filipino Schoolchildren: Implications to Education and National Development. Education Resource Center Occasional Paper

Doronila, M.L. (1992). National Identity and Social Change. Quezon City:

University of the Philippines Press and the Center for Integrative and Development Studies.

Du Gay, P., Hall, S., Janes, L., Mackay, H., \& Negus, K. (Eds.). (1997). Doing Cultural Studies: The Story of the Sony Walkman. London: Sage.

Enriquez, V. (1979). Towards Cultural Knowledge through Cross-Indigenous Methods and Perspectives. Philippine Journal of Psychology, 12(1), 9-15. 
Gebauer, M., Nielsen, H. T., Schlosser, J. T., \& Sørensen, B. (2015). The Absence of Place and Time: Non Place and Placelesness. In Gebauer, M., Nielsen, H. T., Schlosser, J. T., \& Sørensen, B. (Eds.), Non-Place: Representing Placelessness in Literature, Media and Culture. (pp. 5-31). Aalborg Universitetsforlag. Interdisciplinære kulturstudier

Hennig, R. (1983). Philippine Values in Perspective: An Analytical Framework. Philippine Sociological Review, 31(3/4), 55-64.

Hollnsteiner, M. (1970). Reciprocity in the Lowland Philippines. In F. Lynch \& A. de Guzman II (Eds.), Four Readings on Philippine Values (IPC Papers No. 2) (pp. 67-91). Quezon City: Ateneo de Manila Press.

Hunt, C. (Ed.). (1963). Sociology in the Philippine Setting. Quezon City: Phoenix Publishing House.

Jocano, F. L. (1966). Rethinking Smooth Interpersonal Relations. Philippine Sociological Review, 14(4), 282-291.

Kaut, C. (1961). Utang na Loob: A System of Contractual Obligation Among Tagalogs. Southwestern Journal of Anthropology, 18(3), 256-272.

Lawless, R., \& Tan, A. (1968). A Construction of Two Cross-Cultural Studies. Lipunan, 1, 30-37.

Lynch, F. (1970). Social Acceptance, Reconsidered. In F. Lynch \& A. de Guzman II (Eds.), Four Readings on Philippine Values (IPC Papers No. 2) (pp. 1-63). Quezon City: Ateneo de Manila Press.

McClelland, D. (1961). The Achieving Society. University of Illinois at UrbanaChampaign's Academy for Entrepreneurial Leadership Historical Research Reference in Entrepreneurship. Retrieved from SSRN: https://ssrn.com/abstract=1496181

Magos, A. P. (2004). Towards Indigenization: Responses, Challenges and Experiences in the Philippines. In S. Yamashita, J. Bosco, \& J. S. Eades (Eds.), The Making of Anthropology in Southeast Asia (pp. 307-334). New York: Berghahn Books.

Parsons, T. (1964). Social Structure and Personality. New York: The Free Press of Glencoe

Tan, A. L. (1997). Values Research in the Philippines. Philippine Studies, 45(4), 560569.

Tan, M. L. (2010). Philippine Anthropology in a Post-Anthropology Age. In J. Tigno (Ed.), Philippine Social Science Discourses (pp. 7-24). Quezon City: CSSP Publications.

Yacat, J. (2005). Making Sense of Being and Becoming in Filipinos: An Indigenous Psychology Perspective. Philippine Journal of Psychology, 38(2), 19-37. 
Salazar, Z. (1998). "Ukol sa Wika at Kulturang Pilipino." In Mga Piling Diskurso sa Wika at Lipunan, eds. Pamela C. Constantino and Monico M. Atienza. Quezon City: University of the Philippines Press.

Date Received: 17 September 2019 Date of Acceptance: 20 December 